\title{
AC 2007-1373: THE ROLE OF HUMANITIES AND SOCIAL SCIENCES IN THE CIVIL ENGINEERING BODY OF KNOWLEDGE
}

\section{Jeffrey Evans, Bucknell University}

Jeffrey Evans is Professor and Chair of the Department of Civil and Environmental Engineering at Bucknell University.

\section{Daniel Lynch, Dartmouth College}

David Lange, University of Illinois-Urbana Champaign 


\title{
The Role of Humanities and Social Sciences in the Civil Engineering Body of Knowledge
}

\begin{abstract}
The American Society of Civil Engineers has identified a Body of Knowledge (BOK) and is in the process of developing a second version. The first BOK identified the requirement for a broad education, and the second $\mathrm{BOK}$ will provide further structure to this aspect of civil engineering education. This paper explores the role of humanities and social sciences in the education of a $21^{\text {st }}$ century engineer.

Humanities and social sciences along with mathematics and natural science are at the core of liberal learning. The humanities include subjects such as art, history and literature while social science includes subjects such as economics, political science, sociology and psychology. Traditional engineering education emphasizes mathematics and sciences, but the role of humanities and social sciences is not well understood and appreciated by many students and faculty.
\end{abstract}

Humanities and social sciences are a valuable part of a balanced educational experience because they contribute to understanding the context of problems and development of skills in critical thinking. Civil engineers need to consider the context of problems as they design solutions, and so the quality of solutions depend in part on the richness of the engineer's understanding of context. A civil engineer's thinking must be systematic and guided by analysis and assessment of relevant information. A critical thinker 1) raises vital questions and problems, formulating them clearly and precisely; 2) gathers and assesses relevant information, using abstract ideas to interpret it effectively, comes to well-reasoned conclusions and solutions, testing them against relevant criteria and standards; 3) thinks open-mindedly within alternative systems of thought, recognizing and assessing, as need be, their assumptions, implications, and practical consequences; and 4) communicates effectively with others in figuring out solutions to complex problems.

For the civil engineering student educated predominantly in areas of math, science and engineering, the vital questions become math, science and engineering questions. The relevant information to be gathered becomes limited to math, science and engineering data, and the engineer may not think open-mindedly about the alternatives. The engineer might encounter difficulty communicating the questions and answers to a broader audience. Alternatively, an engineer whose education includes substantial grounding in humanities and social sciences is likely to recognize the impact of the engineering decisions not only upon the more narrowly framed math, science and engineering questions but upon the more broadly framed questions informed by social sciences and the humanities.

In summary, a broad education is necessary for $21^{\text {st }}$ century civil engineers to think critically about issues confronting them and develop solutions that are informed not only by math, science and engineering, but by humanities and social sciences as well; to 
implement those solutions effectively within real social contexts; and to evaluate them in humanistic as well as technical terms.

\section{Introduction}

What is the role of engineers in society, and how is that role changing? The National Academy of Engineering Report, The Engineer of $2020^{1}$ identifies three visions for "Our Image and the Profession" as follows:

- By 2020, we aspire to a public that will understand and appreciate the profound impact of the influence of the engineering profession on socio-cultural systems, the full spectrum of career opportunities accessible through an engineering education, and the value of an engineering education to engineers working successfully in non-engineering jobs.

- We aspire to a public that will recognize the union of professionalism, technical knowledge, social and historical awareness, and traditions that serve to make engineers competent to address the world's complex and changing challenges.

- We aspire to engineers who will remain well grounded in the basics of mathematics and science, and who will expand their vision of design through solid grounding in the humanities, social sciences, and economics. Emphasis on the creative process will allow more effective leadership in the development and application of next-generation technologies to problems of the future.

The need for humanities and social sciences education for engineers is evident in each of these statements. The humanities include subjects such as art, history and literature while social science includes subjects such as economics, political science, sociology and psychology. Precise dictionary definitions of humanities and social sciences are included in the Appendix to this paper.

The "aspirational vision" expressed at the summer 2006 ASCE Summit ${ }^{2}$ invokes a vision of professional performance, mutually entrusted and accepted, in the year 2025 (see Table 1). It is not a statement of the status quo, but where we, the civil engineering profession, wish to be. Fulfillment of this vision requires professional activity supported on a balanced base of liberal learning. Failure to provide our students with an engineering education founded upon this balanced base will compromise our ability to perfect this vision, to recruit and prepare the best talent, to express convincingly our value as a profession to the public, and to perform holistically as a profession.

\footnotetext{
${ }^{1}$ National Academy of Engineering, The Engineer of 2020, The National Academies Press, Washington, DC, 2004, 101 pp.

${ }^{2}$ American Society of Engineers, The Vision for Civil Engineering in 2025, ASCE draft report dated January 5, 2007.
} 
Table 1 Vision for the Civil Engineer of 2025

\begin{tabular}{|c|}
\hline $\begin{array}{l}\text { Entrusted by society to } \\
\text { create a sustainable world and enhance the global quality of life, } \\
\text { civil engineers } \\
\text { serve competently, collaboratively, and ethically as master: }\end{array}$ \\
\hline $\begin{array}{l}\text { - planners, designers, constructors, and operators of society's economic and } \\
\text { social engine, the built environment; } \\
\text { - stewards of the natural environment and its resources; } \\
\text { - innovators and integrators of ideas and technology across the public, private, } \\
\text { and academic sectors; } \\
\text { - managers of risk and uncertainty caused by natural events, accidents, and } \\
\text { other threats; and } \\
\text { - leaders in discussions and decisions shaping public environmental and } \\
\text { infrastructure policy. }\end{array}$ \\
\hline
\end{tabular}

The educational base of liberal learning is conventionally divided into four categories: Science, Mathematics, the Humanities, and the Social Sciences. This is a widely accepted articulation of "liberal learning", which implies free and broad inquiry, with intellectual discipline. Along with other established professions, engineering seeks this balanced base.

A well-understood ethic of service to and valued by the public distinguishes a professional from a technical expert. This implies both grounding in appropriate knowledge bases including math, natural sciences, engineering sciences, humanities and social sciences, and refinement through practice. This concept of a professional is broadly shared among other professions such as law and medicine. The ASCE vision asserts this aspiration for civil engineering.

\section{Liberal Learning in civil engineering education}

Liberal learning is a well-established notion, and it is useful to refer to an authoritative definition that applies to a wide audience that includes civil engineering. The following statement of liberal learning was adopted by the Board of Directors of the Association of American Colleges \& Universities, October 1998:

A truly liberal education is one that prepares us to live responsible, productive, and creative lives in a dramatically changing world. It is an education that fosters a well-grounded intellectual resilience, a disposition toward lifelong learning, and an acceptance of responsibility for the ethical consequences of our ideas and actions. Liberal education requires that we understand the foundations of knowledge and inquiry about nature, culture and society; that we master core skills of perception, analysis, and expression; that we cultivate a respect for truth; that we recognize the importance of historical and cultural context; and that we 
explore connections among formal learning, citizenship, and service to our communities.

We experience the benefits of liberal learning by pursuing intellectual work that is honest, challenging, and significant, and by preparing ourselves to use knowledge and power in responsible ways. Liberal learning is not confined to particular fields of study. What matters in liberal education are substantial content, rigorous methodology and an active engagement with the societal, ethical, and practical implications of our learning. The spirit and value of liberal learning are equally relevant to all forms of higher education and to all students.

Liberal learning aims to free us from the constraints of ignorance and bias; and to replace them with a vigorous respect for facts and reason. It prizes curiosity and seeks to expand the boundaries of human knowledge. By its nature, liberal learning is global and pluralistic. It embraces the diversity of ideas and experiences that characterize the social, natural, and intellectual world. To acknowledge such diversity in all its forms is both an intellectual commitment and a social responsibility, for nothing less will equip us to understand our world and to pursue fruitful lives.

The ability to think, to learn, and to express oneself both rigorously and creatively, the capacity to understand ideas and issues in context, the commitment to live in society, and the yearning for truth are fundamental features of our humanity. In centering education upon these qualities, liberal learning is society's best investment in our shared future.

The foregoing statement regarding the goals and attributes of liberal learning must be embraced by civil engineering education to attract, retain and develop our civil engineers of the future. Again quoting,

What matters in liberal education are substantial content, rigorous methodology and an active engagement with the societal, ethical, and practical implications of our learning.

Does this not describe civil engineering education at its best?

\section{Critical Thinking, Communication, and Professional Balance}

The fundamental role of humanities and social sciences in civil engineering education lies in the concepts of liberal learning just described and in the concept of critical thinking. All of us, particularly civil engineers, think about solutions to problems in the context of issues confronting us. If unguided, however, our thinking can be biased, lacking the proper context, and only partially informed. For civil engineers involved in decisionmaking, thinking must be systematic and guided by analysis and assessment of relevant information. A critical thinker ${ }^{3}$ :

- raises vital questions and problems, formulating them clearly and precisely;

\footnotetext{
${ }^{3}$ CriticalThinking.org
} 
- gathers and assesses relevant information, using abstract ideas to interpret it effectively and comes to well-reasoned conclusions and solutions, testing them against relevant criteria and standards;

- thinks open-mindedly within alternative systems of thought, recognizing and assessing, as need be, their assumptions, implications, and practical consequences; and

- communicates effectively with others in figuring out solutions to complex problems.

For a civil engineering student educated predominately in areas of math, science and engineering, the vital questions become math, science and engineering questions. The relevant information to be gathered becomes math, science and engineering data. Having been trained in the methods of solving engineering problems, the engineer may not think open-mindedly about the alternatives. Historically, the engineer might have difficulty communicating the questions and answers to a broader audience. Since liberal learning includes fine arts, literature, philosophy (the humanities) and the social sciences, an engineering student with such general knowledge and the accompanying intellectual skills can bring so much more to the critical thinking process. As a result, the engineer is likely to recognize the impact of the engineering decisions not only upon the more narrowly framed math, science and technical questions but upon the more broadly framed questions informed by social sciences and the humanities. For more detail regarding the areas of study within humanities and social sciences, please refer to the appendix.

Similar points can be made about communications and the proper knowledge base. The communications challenge goes beyond communications among professionals or within teams. Professionals must communicate broadly with the service public, whether local or international. This communication must be a two-way street - active listening and responding to the service population. This communication does not originate in technical terms, nor does it end there. Effective professional communication is premised on a broad foundation in understanding the human condition and its expression. Lacking this foundation, others will be required to "translate" engineering activity to and from the population at large.

\section{A Balanced Body of Knowledge (BOK)}

The ASCE definition of the BOK is "The knowledge, skills, and attitudes necessary to become a licensed professional engineer." Fifteen educational outcomes were identified as making up the BOK for civil engineers. These included eleven outcomes that were nominally similar to ABET Criterion $3(\mathrm{a}-\mathrm{k})$ outcomes ${ }^{4}$ and four additional outcomes specific to civil engineering.

\footnotetext{
${ }^{4}$ Accreditation Board for Engineering and Technology (ABET), Engineering Accreditation Commission, Engineering Criteria 2000, Third Edition, Baltimore Maryland.
} 
Table 2 shows the BOK rubric and the six levels of Bloom's cognitive achievement. ${ }^{5}$ The levels of achievement expected to be accomplished prior to licensure are shown. For instance, under "Knowledge", (B) is indicated. This means that the level of achievement should be achieved during the baccalaureate program of study. A symbol of $(\mathrm{M} / 30)$ is indicated and should be achieved during either the master's degree program or alternatively included in the 30 hours of post-baccalaureate, non-degree academic classes which are taken by the student/engineer. Pre-licensure experience (E), which is shorthand for this level, is to be achieved during the pre-professional practice experience phase prior to licensure. Usage of the rubric format, including the adherence to the Bloom's action verbs, is expected to result in an easily understood document that will have little ambiguity regarding what is expected, and when it is to be accomplished.

${ }^{5}$ ASCE Levels of Achievement Subcommittee of the Committee on Academic Prerequisites for Professional Practice. Levels of Achievement Applicable to the Body of Knowledge. September, 2005. 

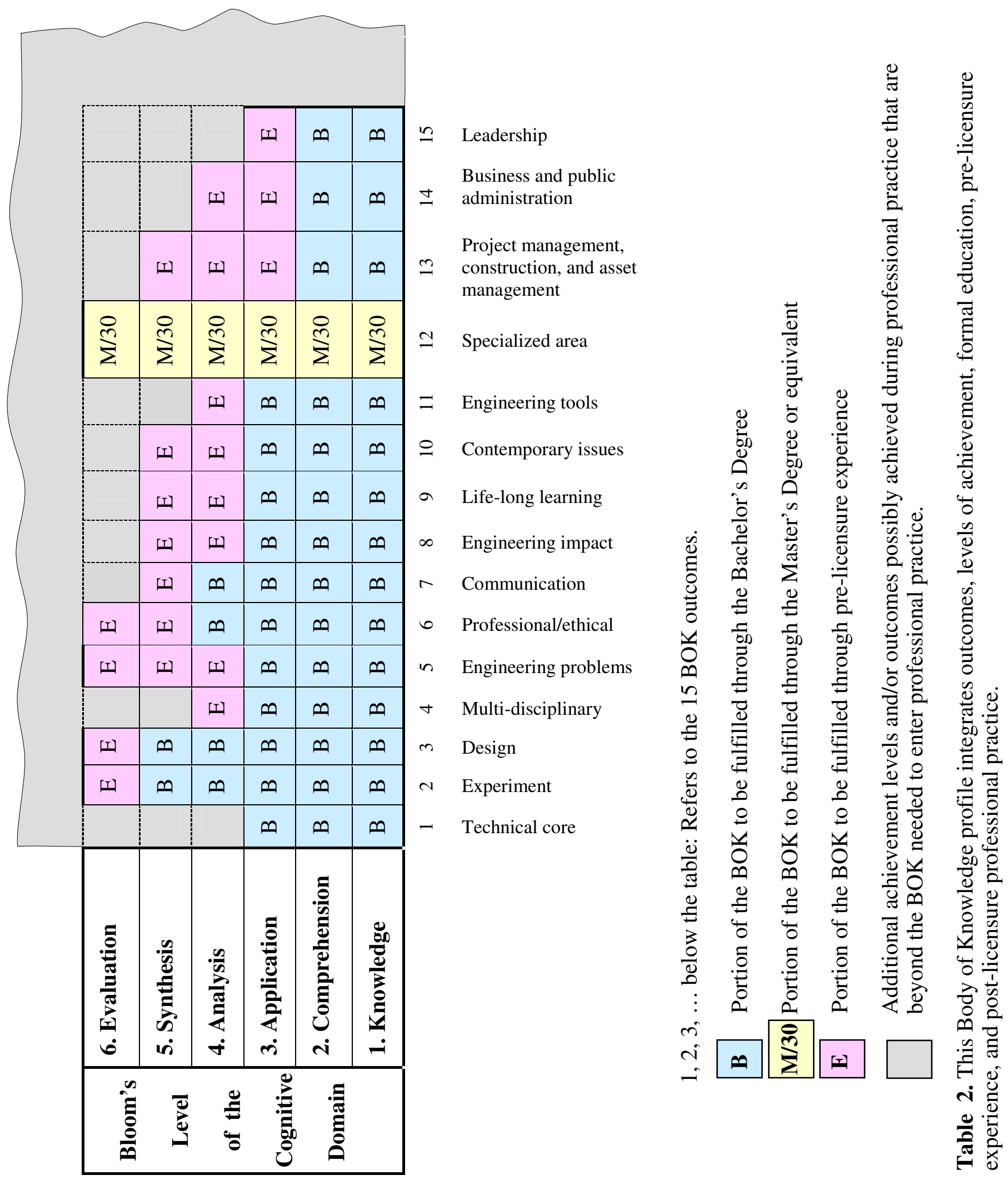
Civil engineering education is strongly influenced by the requirements of ABET. ASCE has taken a proactive stance in this regard through the development and publication of the Body of Knowledge ${ }^{6}$ (BOK) to influence future ABET criteria but whose educational outcomes closely followed those of ABET2000 ${ }^{7}$. Interestingly, prior to ABET2000, ABET criteria explicitly required the inclusion of $1 / 2$ year of study of humanities and social sciences. The explicit requirement is no longer the case. ASCE is currently working on revisions to the $\mathrm{BOK}$ and plans to publish a second edition to the $\mathrm{BOK}$ in early 2008 .

As argued in the first portion of this paper, the technical component of the education of future civil engineers needs to be supported by math, natural science, humanities and social science. Presented on Figure 1 is a graphic that attempts to capture this central idea.

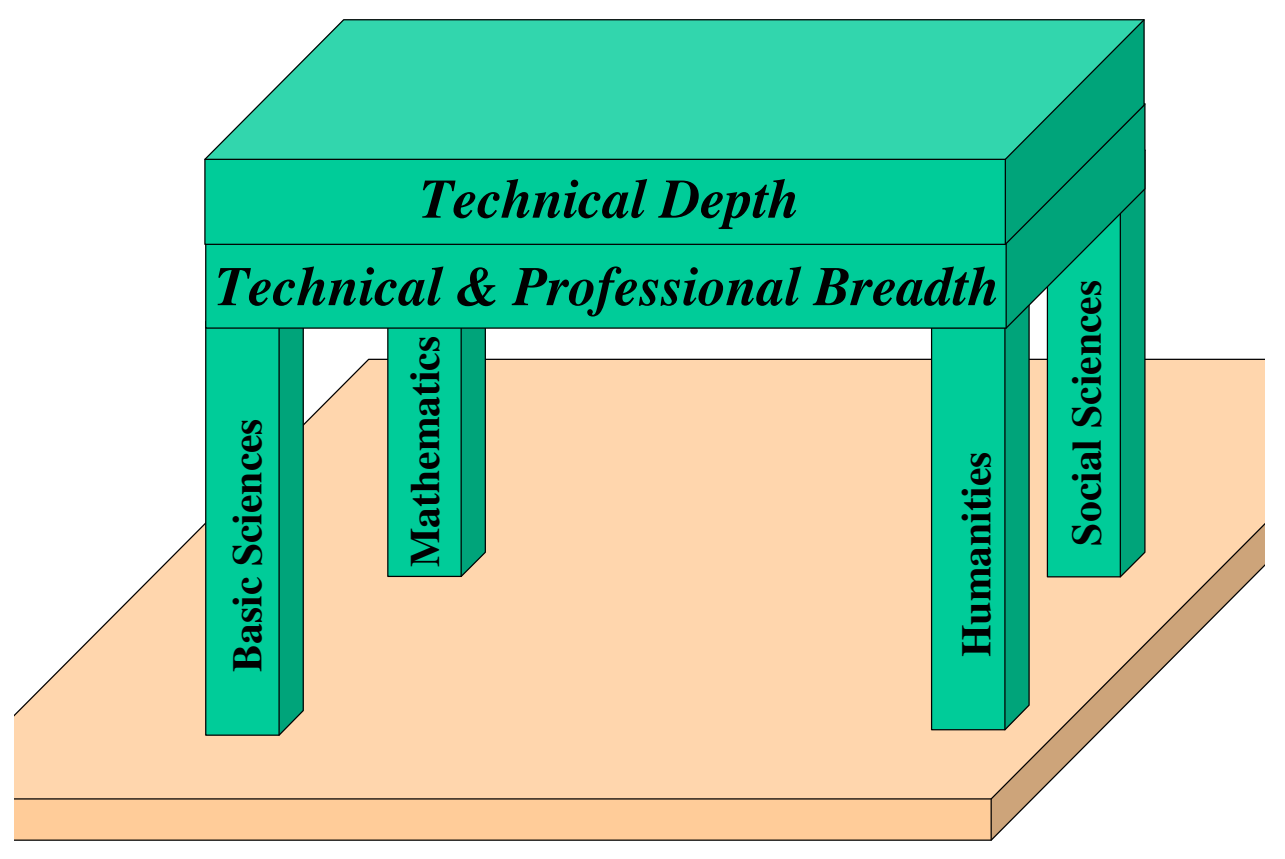

\section{Figure 1: Future Education for Civil Engineers}

In this graphic, the technical and professional components of a civil engineering education are supported by four legs that represent the established dimensions of liberal learning in higher education. These four legs also form the underlying support for specialized education in law, medicine, and other professions. Each profession balances the education of their students by the appropriate blend of 'strength' in the various 'legs'.

\footnotetext{
${ }^{6}$ ASCE Body of Knowledge Committee of the Committee on Academic Prerequisites for Professional Practice, Civil Engineering Body of Knowledge for the $21^{\text {st }}$ Century, January 12, 2004, $128 \mathrm{pp}$.

${ }^{7}$ Accreditation Board for Engineering and Technology (ABET), Engineering Accreditation Commission, Engineering Criteria 2000, Third Edition, Baltimore Maryland.
} 
Relative to these legs, Vest ${ }^{8}$, relates two "pivotal" developments in engineering education since World War II: the development of the science base of "engineering science"; and the incorporation of the humanities and social sciences in support of the "twenty-first-century view of engineering systems, which surely are not based solely on physics and chemistry." We observe here an increasing reliance on the humanities and social sciences legs and the obligation to develop these within the profession broadly, as a matter of basic professional competence.

The $20^{\text {th }}$ century has seen a major expansion in the math and science 'legs' that support civil engineering education. Reflecting this heritage, the natural science and math 'legs' are separately and explicitly articulated in the current ABET outcome 3(a) [An ability to apply knowledge of mathematics, science, and engineering]. The importance of math and natural science to civil engineering education is further emphasized by splitting this ABET outcome 3(a) into four separate outcomes in the current working draft of the second edition of the BOK. In addition there are ABET outcomes 3(c) [An ability to design a system, component, or process to meet desired needs], 3(e) [An ability to identify, formulate, and solve engineering problems] and $3(\mathrm{k})$ [An ability to use the techniques, skills, and modern engineering tools necessary for engineering practice] where the need for math and natural science support is implied. The other two legs, humanities and social sciences, are widely agreed to be necessary foundations for professional outcomes; yet the humanities and the social sciences legs are not explicit in ABET outcomes. ABET outcome 3(h) does require the "Broad education necessary to understand the impact of engineering solutions in a global and societal context" and this outcome was included in the BOK. The absence of explicit outcomes for Humanities and Social Sciences is consistent with the classical impression of an engineer well grounded in technical issues only. This is the historical stereotype and the profession needs to correct this stereotype. Recently, outcomes for Humanities and Social Sciences have been accepted by the ASCE on the second edition of the BOK. Rising to the professional aspirations expressed by ASCE, will require explicit expression of the importance of Humanities and Social Sciences in the second edition of the BOK.

\section{Humanities and Social Sciences Outcomes and Commentary}

In order to meet the need for education in humanities and social sciences, the current BOK committee is considering the adoption of additional outcomes that specifically address humanities and social science. The overviews of these proposed outcomes are presented as Tables 3 and 4 for Humanities and Social Sciences, respectively.

\footnotetext{
${ }^{8}$ Nov. 13 '06 C. Vest, "Educating Engineers for 2020 and Beyond"; in Educating the Engineer of 2020, NAE, 2005, pp 164-165.

${ }^{9}$ C. Vest, The Bridge, Summer 2006, p.40
} 


\section{Table 3 Humanities}

Overview: To be effective, professional civil engineers must be critical thinkers with the ability to raise vital questions and problems, formulate them clearly and appropriately gather and assess relevant information, use abstract ideas to interpret the information effectively and come to well-reasoned conclusions and solutions, testing them against relevant criteria and standards. Professional civil engineers must think open-mindedly within alternative systems of thought, recognizing and assessing, as need be, the assumptions, implications, and practical consequences. They must be informed by not only mathematics and natural sciences but the Humanities, the disciplines that study the human aspects of the world such as philosophy, history, literature, visual arts, performing arts, language and religion. This outcome is intended to guide students to make connections between their technical education and their education in the humanities.

The formal education process sets the stage for professional achievement. In practice, our profession involves varying degrees of integration of humanities such as ethical, aesthetic, and historical factors. Engineers must be able to recognize and incorporate these human factors into the development and evaluation of solutions to engineering and societal problems. Continued development of professional competence must come from life-long learning, mentorship from senior engineers and practical experience, and involvement with the local community, grounded on a firm foundation in and a recognition of the importance of the Humanities.

B: Upon graduation from a baccalaureate program, an individual must be able to formulate applicable criteria grounded in the Humanities and use them in the development of a solution to engineering problems appropriate to civil engineering. (L3)

The formal education process at the undergraduate level must include an introduction to humanities in order for the student to develop an appreciation of their importance in developing engineering solutions. All students cannot study all of the humanities; rather, students first must be able to recognize and identify factual information from two areas of humanities. Students should be able to explain concepts in at least one area of humanities in order for them to explain how this can inform and impact their engineering decisions. Students should be able to apply their knowledge of humanities by using them in the development of a solution to engineering problems appropriate to civil engineering. Examples of opportunities to demonstrate this ability include incorporating application of philosophy in engineering ethics, visual arts in the aesthetics of structures, language in the globalization of engineering, history in the study of the past accomplishments of society through civil engineering. For example, humanities issues can be raised and assessed in civil engineering courses such as transportation and environmental engineering and in a capstone design course. 


\section{Table 4 Social Sciences}

Overview: Engineering services are delivered to society through social mechanisms and institutions. The Social Sciences are the systematic study of these social phenomena; example disciplines include economics, political science, sociology, and psychology. Note that some studies in History can be categorized as social sciences. Professional civil engineers must work within a social framework; understanding it is foundational to effective professionalism, alongside the three other foundational areas (i.e., Math, Science, Humanities). This outcome is intended to guide students to make connections between their technical education and their education in the social sciences.

The formal education process sets the stage for individuals to become effective professionals. In practice, virtually all projects and design work involve varying degrees of integration of social sciences knowledge, such as economic and socio-political aspects. Engineers must be able to recognize and incorporate these considerations into the development of solutions to engineering problems. Continued development of professional competence must come from life-long learning, mentorship from senior engineers and practical experience, grounded on a firm foundation in and a recognition of the importance of the Social Sciences.

\section{B: Upon graduation from a baccalaureate program, an individual must be able to} formulate criteria from the domain of social sciences and use them in the development of solutions to engineering problems appropriate to civil engineering. (L3)

The formal education process at the undergraduate level must include an introduction to social sciences in order for the student to develop an appreciation of their importance in the development of engineering solutions. All students cannot master all of the social sciences; rather, students first must be able to recognize and identify factual information from two areas of social science. Students should be able to explain the concepts in at least one area of social science in order for them to explain how this area of social science can inform their engineering decisions. Students should be able to apply their knowledge of social sciences by formulating applicable social criteria and using the criteria in the development of a solution to fundamental engineering problems appropriate to civil engineering. Examples of knowledge from social sciences that might be applied in engineering include economic, safety and security considerations. Examples of opportunities to demonstrate this ability includes incorporating application of social sciences in civil engineering courses such as transportation, environmental engineering and in a capstone design course. 
Both outcomes require an engineering student to have achieved proficiency at Level 3 "Application" of Bloom's taxonomy. It is assumed that this is achieved as part of the Bachelor of Science in Civil Engineering.

How does a program achieve these outcomes? How does this change the current smorgasbord of humanities and social science electives from which our students choose? These and other issues remain to be explored further. Certainly, the role of humanities and social sciences in the curriculum is not a new issue ${ }^{10}$ but it is an increasingly important one.

\section{Summary and Conclusions}

The ability to function as a Professional Engineer requires broad educational preparation if problems are to be properly identified and solved, and solutions evaluated and accepted, by society. An engineer cannot be aloof from the people that he or she serves; nor from the social context in which engineering needs are expressed and works must function. The undergraduate civil engineering education is strongly grounded in math and science in support of engineering and profession studies. These two components of an engineer's education are only part of the four components of liberal learning which also includes humanities and social sciences. It order to achieve the vision for civil engineering, we must embrace liberal learning and the humanities and social sciences.

\section{Acknowledgements}

The authors appreciate the input received on the development of this paper and for their careful review of earlier drafts. Specifically, Jeffrey Russell, Thomas Lenox, and James O'Brien served with the authors on a subcommittee of the BOK2 Committee and their input helped shaped the final product. A special note of appreciation goes to Thomas Lenox for preparation of Figure 1. Of course, the ideas and opinions expressed in this paper are those of the authors and do not necessarily represent the views of ASCE.

${ }^{10}$ Van Treuren, K. and Eisenbarth, S. "Engineering Education in a Liberal Arts Enviroment at Baylor University," Proceedings of the 2002 ASEE Annual Conference and Exposition, Montreal, Quebec, Canada, June 16-19, 2002. 


\section{Appendix - Definitions}

For the purposes of this paper, it is useful to clarify the definitions of the Humanities and Social Sciences as they pertain to the education of civil engineers.

Humanities: includes disciplines that study the human condition such as Philosophy, History, Literature, Visual Arts, Performing Arts, Language and Religion.

Social Sciences: includes disciplines that study the human aspects of the world such as Economics, Political Science, Sociology, Psychology and Anthropology.

In support of the above working definitions, two dictionary definitions are provided below that are consistent with and in support of the working definitions provided above.

\section{Source 1: Oxford American Dictionaries}

humanity noun ( pl. -ties)

1 the human race; human beings collectively : appalling crimes against humanity.

- the fact or condition of being human; human nature : a few moments when Soviets and Canadians shared their common humanity.

2 humaneness; benevolence: he praised them for their standards of humanity, care, and dignity.

3 ( humanities) learning or literature concerned with human culture, esp. literature, history, art, music, and philosophy.

ORIGIN Middle English : from Old French humanity, from Latin humanitas, from humanus (see human ).

social science noun

the scientific study of human society and social relationships.

- a subject within this field, such as economics or politics.

Source 2: The American Heritage ${ }^{\circledR}$ Dictionary of the English Language humanity noun (pl. hu·man'i-ties)

1. Humans considered as a group; the human race.

2. The condition or quality of being human.

3. The quality of being humane; benevolence.

4. A humane characteristic, attribute, or act.

5. humanities a. The languages and literatures of ancient Greece and Rome; the classics.

b. Those branches of knowledge, such as philosophy, literature, and art, that are concerned with human thought and culture; the liberal arts.

ETYMOLOGY: Middle English humanite, from Old French, from Latin hmnits, from hmnus, human. See human.

social science noun

1. The study of human society and of individual relationships in and to society.

2. A scholarly or scientific discipline that deals with such study, generally regarded as including sociology, psychology, anthropology, economics, political science, and history. 